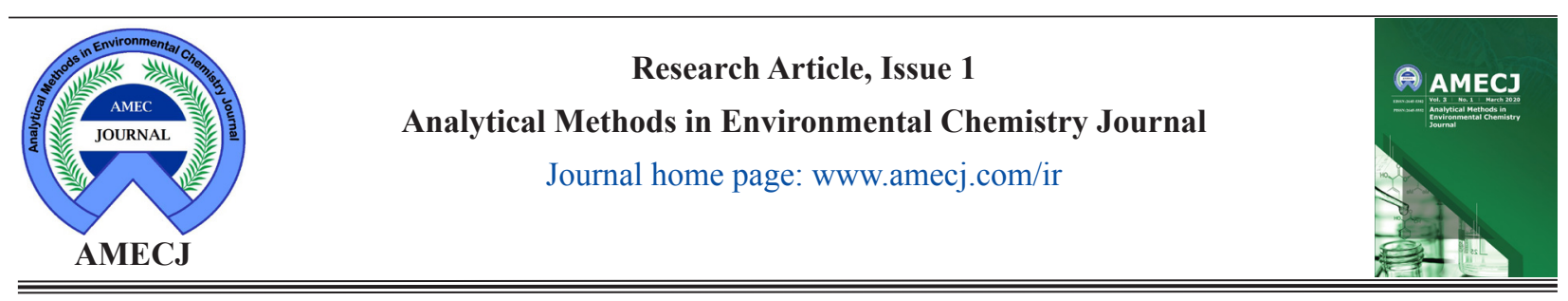

\title{
Extraction and determination of benzene from waters and wastewater samples based on functionalized carbon nanotubes by static head space gas chromatography mass spectrometry
}

\author{
Shahnaz Teimooria ${ }^{a}$ Amir Hessam Hassani ${ }^{b, *}$, Mostafaa Panaahie ${ }^{b}$ \\ a PhD student of environmental engineering, Faculty of Natural Resources and Environment, Science and Research Branch, Islamic Azad University, Tehran, Iran \\ ${ }^{b}$ Department of environmental engineering, Faculty of Natural Resources and Environment, Science and Research Branch, Islamic Azad University, Tehran, Iran
}

\section{A R T I C L E I N F O:}

Received 30 Nov 2019

Revised form 10 Jan 2020

Accepted 11 Feb 2020

Available online 26 Mar 2020

Keywords:

Benzene,

Water,

Dispersive micro solid phase extraction,

Phenyl sulfonic acid,

Carbon nanotubes,

Static head space gas chromatography mass spectrometry

\begin{abstract}
A B S T R A C T
Removal of benzene, as hazardous pollutants from waters and wastewater is a main problem of environment contamination due to high risk factor in human health. In this study, the phenyl sulfonic acid (PhSA) modified carbon nanotubes (CNTs) were used for benzene removal from waters by dispersive micro solid phase extraction method (D- $\mu \mathrm{SPE}$ ). Due to adsorption mechanism, the polar $-\pi$ and $\pi-\pi$ electron donor-acceptor interactions was provided between the aromatic ring of benzene with the surface sulfonic acid groups $\left(\mathrm{SO}_{3} \mathrm{H}\right)$ and phenyl ring (-C6H5) of CNTs, respectively. Therefore, $20-100 \mathrm{mg}$ of sorbent, concentration of benzene (0.1-10 $\left.\mathrm{mg} \mathrm{L}^{-1}\right), \mathrm{pH}$ (1-12) and contact time (5-120 min) were investigated and optimized for benzene removal from water samples in static system. The concentration of benzene in water was determined by static head space gas chromatography mass spectrometry (SHS-GC-MS). The results showed, the LangmuirFreundlich (LF) isotherm provided the best fit for benzene sorption. By using the Langmuir model, the maximum adsorption capacity of $157.34 \mathrm{mg} \mathrm{g}^{-1}$ and $22.86 \mathrm{mg} \mathrm{g}^{-1}$ was achieved for benzene removal from waters with CNTs@PhSA and CNTs, respectively. The method was validated by certified reference material in waters.
\end{abstract}

\section{Introduction}

Benzene is a chemical aromatic and flammable compound which is a natural component of petroleum-derived products. It is one of the most highly used groups of raw materials and solvents in numerous chemical synthesis processes, and manufacturing industries [1-3] .The presence of benzene in groundwater is due to petroleum product's leakage into water sources and leaking underground storage tanks and pipelines [4, 5]. According to the US Environmental Protection * Corresponding Author: Amir Hessam Hassani

Email: ahh1346@gmail.com

https://doi.org/10.24200/amecj.v3.i01.91
Agency (EPA), benzene is one of the primary pollutants that adversely affects human health [6] .It is a serious health problem, causing several human diseases such as cancer, central nervous system disorders, leukemia, respiratory problems, skin and eye diseases [7-9]. Considering these health concerns and based on U.S.EPA announcement, the standard level of benzene in drinking water should not exceed $5 \mu \mathrm{g}^{-1}$ [6]. Therefore, it is crucial to remove this pollutant from water supplies, especially surface water, and ground waters. Since their discovery by Iijima et al in 1991 [10], Carbon nanotubes (CNTs) have been in a major area of 
interest within many contexts, especially in water treatment. CNTs are graphitic carbon sheets folded into hollow cylinders with diameters and lengths in nanometer and micrometer scales, respectively [11-13]. Unique properties of CNTs including hydrophobicity, high specific surface area, hollow and layered structure and existence of $\pi$-electrons on their surface make them superior adsorbents for removal of contaminants [14-16]. Some studies put further steps and investigated the effect of CNT's modification on their adsorption performance. $\mathrm{Lu}$ et al. showed that $\mathrm{NaOCl}$-oxidized CNTs have significant adsorption capacity in comparison to other types of carbon adsorbents [17]. Su et al conducted a research in which multiwalled carbon nanotubes were oxidized by sodium hypochlorite solution and turned to a new adsorbent with enhanced adsorption performance [18]. These studies show high affinity of CNTs toward organic compounds, and open new avenue for developing carbon nanotube technologies to treat benzene and other organic chemicals in water. However, there is a high number of CNTs that can be used to remove benzene from water supplies and which subtype of CNTs family can have the most effective adsorption capacity, is still unknown. To our knowledge, so far, there is no data about the adsorption capacity of phenyl sulfonic acid (PhSA) modified hybrid carbon nanotubes (CNTs). Therefore, the main objective of this study is using phenyl sulfonic acid (PhSA) modified hybrid carbon nanotubes (CNTs) to remove benzene from water sources by dispersive solid phase extraction method.

\section{Experimental}

\subsection{Material and methods}

Gas chromatography based on mass detector (GC-MS) and air sample loop injection (ASL) was used for benzene determination by static head space accessory (SHS-GC-MS, Netherland). The headspace may be sampled using a gas tight syringe of appropriate volume. Gas-tight syringe (GTS) was used for determination VOCs ${ }^{1}$ from water samples by shaking and heating samples.

1- Volatile organic compound
The auto-sampling of GTS units can retrofit to a standard GC with a split/split less injector. The GTS auto-sampler is beneficial for use with diverse samples. The Agilent 7890A GC can accommodate up to three detectors identified as front detector, back detector, and auxiliary detector. This model of GC design with three detectors in front, back, and auxiliary (FID, TCD, MS) and equipped with a split injector with poly di-methyl siloxane column (Table 1). The mass detector chosen was selected for benzene analysis in gas/liquid. Before injection, Slide the plunger carrier down until it is completely over the syringe plunger, and tighten the plunger thumb screw until finger- tight. The injector temperature was adjusted to $190^{\circ} \mathrm{C}$ and the detector temperature at $240^{\circ} \mathrm{C}$. The $\mathrm{GC}$ oven temperature was programmed from $25^{\circ} \mathrm{C}$ to $250^{\circ} \mathrm{C}$ which was held for $12 \mathrm{~min}$. Hydrogen(Cas number: 1333-74-0) as the carrier gas was used at a flow rate of $1.0 \mathrm{~mL} \mathrm{~min}{ }^{-1}$. The scanning electron microscopy (SEM) and Raman spectra were recorded by electron microscopy and spectrometer of CNTs@ $\mathrm{PhSA}$ (Bruker). Fourier transformed infrared spectroscopy (FTIR, IR-200 Thermo-Nicolet 2.2) in $\mathrm{KBr}$ in the range $400-4000 \mathrm{~cm}^{-1}$ was used to confirm the covalently bound benzenesulfonic acid (CAS N: 98-11-3) group on the CNT surface. Transmission electron microscopy (TEM, Philips) with a conventional $15 \mathrm{kV}$ electron microscope was used to analyze the surface morphology of CNTs@ PhSA. X-ray diffraction (XRD; Panalytical) was used for XED patterns with wavelength 0.15405 nm for CNTs@PhSA. The intensity was measured by step scanning in a $2 \theta$ range of $5-80^{\circ}$. Benzene (CAS N: 71-43-2; $\mathrm{C}_{6} \mathrm{H}_{6}$ ) purchased from Sigma Aldrich. Five calibration solutions of benzene were prepared and the approximate concentrations of benzene were $0.1,0.2,0.5,1.0,5,0$ and $10 \mathrm{mg} \mathrm{L}^{-1}$. The other chemicals with high purity $(99 \%)$ were purchased from Sigma (Germany). The analytical grade solvents such as benzene, chloroform, (CAS $\mathrm{N}$ : 67-66-3), 4-benzenediazoniumsulfonate (CAS: 305-80-6), acetone (CAS N: 67-64-1), $\mathrm{HNO}_{3}$ (CAS N:7697-37-2), HCl (CAS N: 7647-01-0), $\mathrm{H}_{2} \mathrm{SO}_{4}(\mathrm{CAS} \mathrm{N}:$ 7664-93-9), acetic acid (CAS N: 
64-19-7) and $\mathrm{NaOH}$ (CAS N:1310-73-2) were also from Merck.CNTs@PhSA was synthesized in RIPI laboratory, Iran. Ultrapure water $(18 \mathrm{M} \Omega \cdot \mathrm{cm})$ was obtained from Millipore continental water system (Millipore, USA). Samples of water and wastewater collected in polyethylene bottles were filtered through Millipore cellulose membrane filter $(0.45 \mu \mathrm{m}$ porosity $)$ to remove suspended particulate matter.

\subsection{Synthesis of phenyl sulfonic acid modified hybrid carbon nanotubes}

High-purity CNTs were synthesized by use of camphor, an environmentally friendly hydrocarbon as a carbon source using chemical vapor deposition method on $\mathrm{Co}-\mathrm{Mo} / \mathrm{MgO}$ nanocatalysts. The nanocatalyst was synthesized by sol-gel method. HCNTs were grown at temperatures of about $900-1000^{\circ} \mathrm{C}$ in $45-60 \mathrm{~min}$. Concentration of active metals was $5-10 \%$. The nanocatalyst $(\mathrm{Co}-\mathrm{Mo} /$ $\mathrm{MgO}$ ) was prepared by our special sol-gel method [19]. For functionalization of CNTs with phenyl$\mathrm{SO}_{3} \mathrm{H}$ (CAS N: 98-11-3) group, CNTs surface was activated by $50 \% \mathrm{HNO}_{3}$ (CAS N: 7697-372) for $1 \mathrm{~h}$ and washed with ultrapure water many times. The diazotization reaction was used for functionalization as follows; $0.03 \mathrm{~mol}$ of sulfanilic acid CAS N: 121-57-3) was dispersed in $300 \mathrm{~mL}$ of $1 \mathrm{M} \mathrm{HCl}$ (7647-01-0) in a three-necked ground flask [20]. The flask was kept in an ice water bath and the temperature controlled around $3{ }^{\circ} \mathrm{C}$ under stirring. Then, $33 \mathrm{~mL}$ of $1 \mathrm{M} \mathrm{NaNO}_{2}(\mathrm{CAS} \mathrm{N}$ : 7632-00-0) was added dropwise into the mixture and stirred for $1 \mathrm{~h}$ at the same temperature. The resulting precipitate was filtered and washed
Table 1. The conditions of GC-MS for determination benzene

\begin{tabular}{|c|c|}
\hline GC-MS & Conditions \\
\hline Model & Agilent, 7890A \\
\hline Sensitivity & $0.1-20 \mathrm{ng}$ \\
\hline Injection Volume & 1-5 $\mu \mathrm{L} ; 10: 1$ split \\
\hline Split ratio & $2: 1$ \\
\hline Column & 30 meter, $0.32 \mathrm{~mm} \times 0.25 \mu \mathrm{m}$ \\
\hline Temperature Injector & $220^{\circ} \mathrm{C}$ \\
\hline Detector FID & $230^{\circ} \mathrm{C}$ \\
\hline Program, time $=5.0 \mathrm{~min}$ & 25 to $100^{\circ} \mathrm{C}$ at $25^{\circ} \mathrm{C}$ per min \\
\hline Carrier Gas & $\mathrm{N}_{2}, 1 \mathrm{~mL} \mathrm{\operatorname {min } ^ { - 1 }}$ \\
\hline $\begin{array}{l}\text { Column Oven Pressure } \\
\text { Pulse }\end{array}$ & $60^{\circ} \mathrm{C}$ \\
\hline Column Flow & $6 \mathrm{ml} \mathrm{min}{ }^{-1}$ \\
\hline Retention Time & $8.153(\min )$ \\
\hline Run Time (Min) & $19.125(\mathrm{~min})$ \\
\hline Flow Rate $\mathrm{N}_{2}$ & $30\left(\mathrm{~mL} \mathrm{~min}^{-1}\right)$ \\
\hline Flow Rate $\mathrm{H}^{2}$ & $34\left(\mathrm{~mL} \min ^{-1}\right)$ \\
\hline Injection size & $1-5 \mu \mathrm{L}$ \\
\hline Flow Rate air & $200-400\left(\mathrm{~mL} \mathrm{~min}^{-1}\right)$ \\
\hline
\end{tabular}

with deionized water. In the following step, $5 \mathrm{~g}$ of 4-benzenediazonium sulfonate and $180 \mathrm{mg}$ of activated CNTs were added into $120 \mathrm{~mL}$ of mixture of water and ethanol $(1: 1, \mathrm{v} / \mathrm{v})$ at $3^{\circ} \mathrm{C}$. Subsequently, $60 \mathrm{~mL}$ of $\mathrm{H}_{3} \mathrm{PO}_{2}$ aqueous solution (50 wt.\%) was added to the mixture and stirred for $30 \mathrm{~min}$. After this time, another $60 \mathrm{~mL}$ of $\mathrm{H}_{3} \mathrm{PO}_{2}(\mathrm{CAS} \mathrm{N}$ : $6303-$ 21-5) was added and stirred for $1 \mathrm{~h}$. The resulting mixture was washed with deionized water and dried overnight in an oven at $80^{\circ} \mathrm{C}$ (Fig. 1).

\subsection{Extraction Procedure}

The CNTs@PhSA nanostructures based on D- $\mu$ SPE method was used for extraction of benzene from waters (Fig. 2). First, 10 mg of CNTs@PhSA or

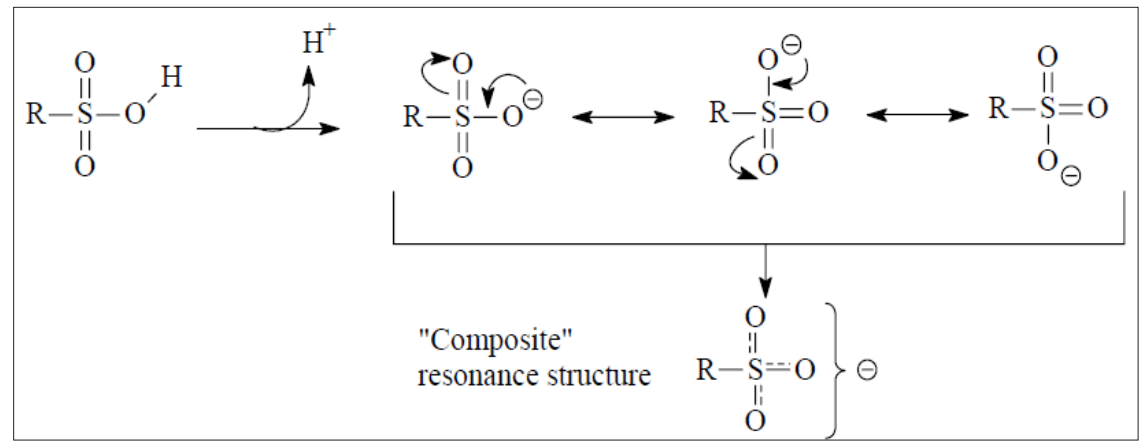

Fig. 1. Synthesis of composite with resonance structure 
CNTs nanostructures was put on $5 \mathrm{~mL}$ of water samples with different benzene standard solution (0.1--10 $\left.\mathrm{mg} \mathrm{L}^{-1}\right)$ in GC vial. The mixture shacked for $10 \mathrm{~min}$ by magnetic shaker accessory (MSA) and after centrifuging for $3 \mathrm{~min}$ (3500rpm), the solid phase separated from liquid phase and finally the benzene concentration in water sample was determined by static head space gas chromatography mass spectrometry (SHS-GC-MS). After extraction, the recoveries were calculated with the ratio of initial/final concentration of benzene in vial GC by SHS-GC-MS (Eq. A). In addition, adsorption capacity and removal efficiency (RE) was calculated by equation Eq. B and Eq. C. X is the initial concentration of benzene in solution and $\mathrm{Y}$ is final concentration of benzene which determinate by SHS-GC-MS in water samples. The adsorption capacity (AC) of benzene $\left(\mathrm{mg} \mathrm{g}^{-1}\right)$ and, the removal efficiency of benzene (\%) was shown in Eq. B and Eq. C. The $\mathrm{C}_{\mathrm{i}}\left(\mathrm{mg} \mathrm{L}^{-1}\right)$ and $\mathrm{C}_{\mathrm{f}}\left(\mathrm{mg} \mathrm{L}^{-1}\right)$ are the concentration of benzene before and after extraction procedure, Vs (L) is the sample volume, and mass $(\mathrm{g})$ is the amount of CNTs@PhSA.

$$
\begin{aligned}
& R=\frac{X}{Y} \times 100 \\
& A C=\frac{\left(C_{i}-C_{f}\right) \times V s}{\text { Mass }} \\
& R E(\%)=\frac{C_{i}-C_{f}}{C_{i}} \times 100
\end{aligned}
$$

\section{Results and discussion}

Mechanism of extraction of benzene with CNTs@ $\mathrm{PhSO}_{3} \mathrm{H}$ was achieved based on $\pi-\pi$ stacking between aromatic chain and $\mathrm{S}=\mathrm{O}$ bond of CNTs@ $\mathrm{PhSO}_{3} \mathrm{H}$ and $\mathrm{SO} \mathrm{b}$ and molecular of benzene in waters by sandwich or $\mathrm{T}$ shaped $\pi-\pi$ bonding (Fig. $3)$.

\subsection{Characterization}

Figure $4(a, b)$ showed the SEM and TEM images revealed the CNTs@ $\mathrm{PhSO}_{3} \mathrm{H}$ consist of randomly aggregated and crumpled thin tubes which are closely associated with each other forming a disordered solid, and it can be inferred that the functionalization process does not change the general structure of HCNTs. The FTIR spectrum of the $\mathrm{CNTs} @ \mathrm{PhSO}_{3} \mathrm{H}$ sample showed the $\mathrm{O}=\mathrm{S}=\mathrm{O}$, $\mathrm{OH}$ as a broad peak, $\mathrm{C}=\mathrm{C}$ and $\mathrm{C}-\mathrm{S}$ bond which was confirmed the $\mathrm{SO}_{3}$ bond in CNTs (Fig. 5). Raman spectroscopy is a useful technique for the characterization of carbon nanotubes quality. Raman patterns of CNTs@ $\mathrm{PhSO}_{3} \mathrm{H}$ confirm the presence of CNTs (Fig. 6) and XRD image showed the hexagonal structures in CNTs@ $\mathrm{PhSO}_{3} \mathrm{H}$. After the attachment of $\mathrm{SO}_{3} \mathrm{H}$ groups on the carbon wall of CNTs the three peaks which confirms the functionalization of $\mathrm{SO}_{3} \mathrm{H}$ on CNTs@Ph have not any changes on the structure of CNTs (Fig. 7).

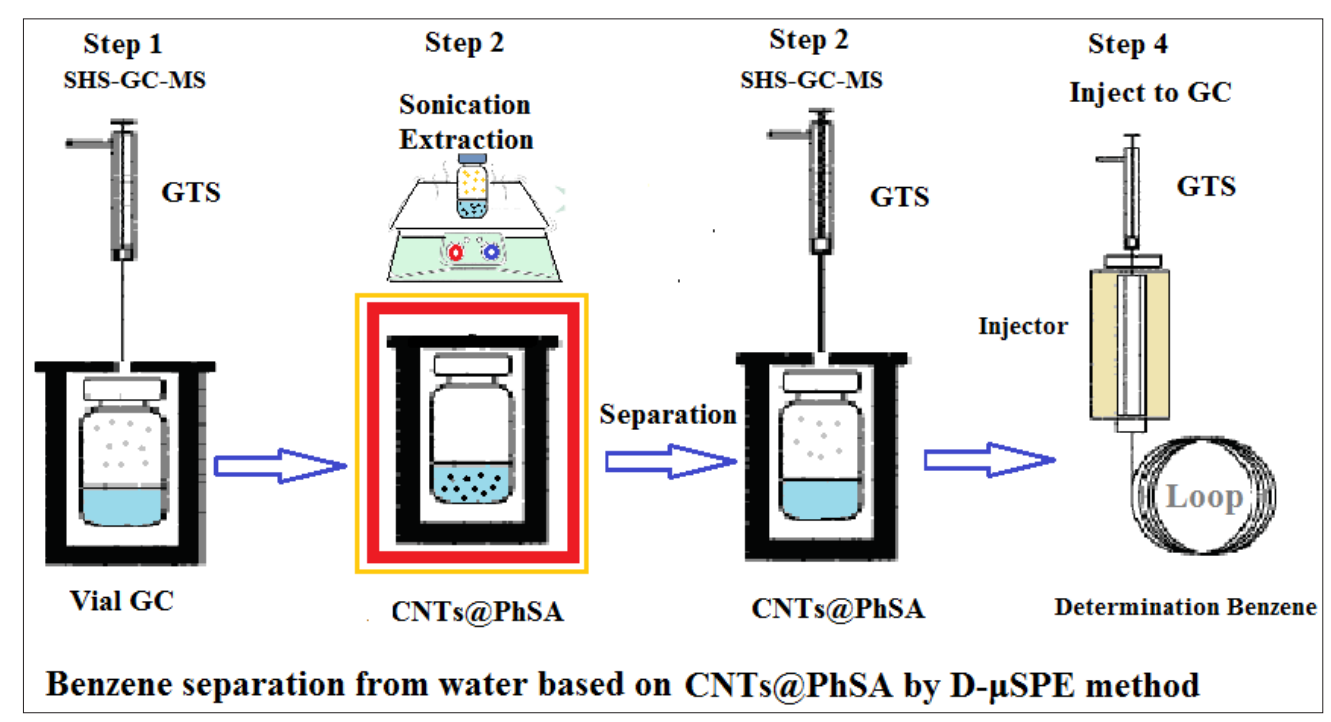

Fig. 2. Benzene extraction from waters based on CNTs@PhSA by D- $\mu$-SPE method 


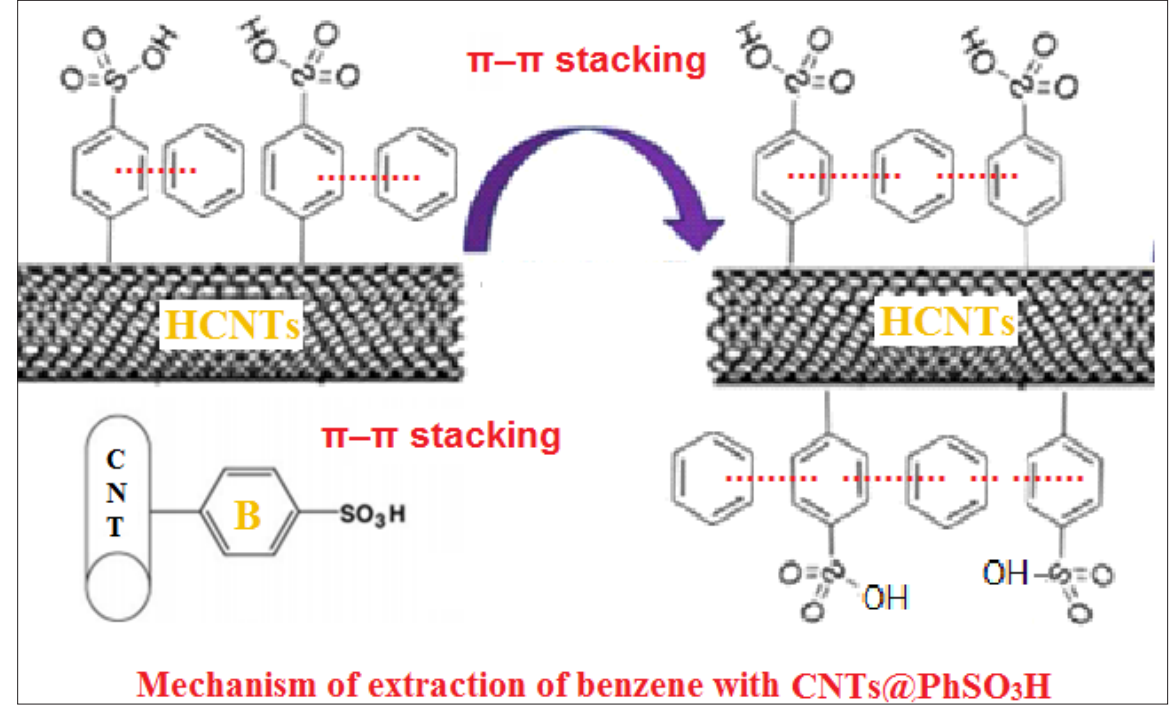

Fig. 3. Mechanism of extraction of benzene with CNTs@ $\mathrm{PhSO}_{3} \mathrm{H}$

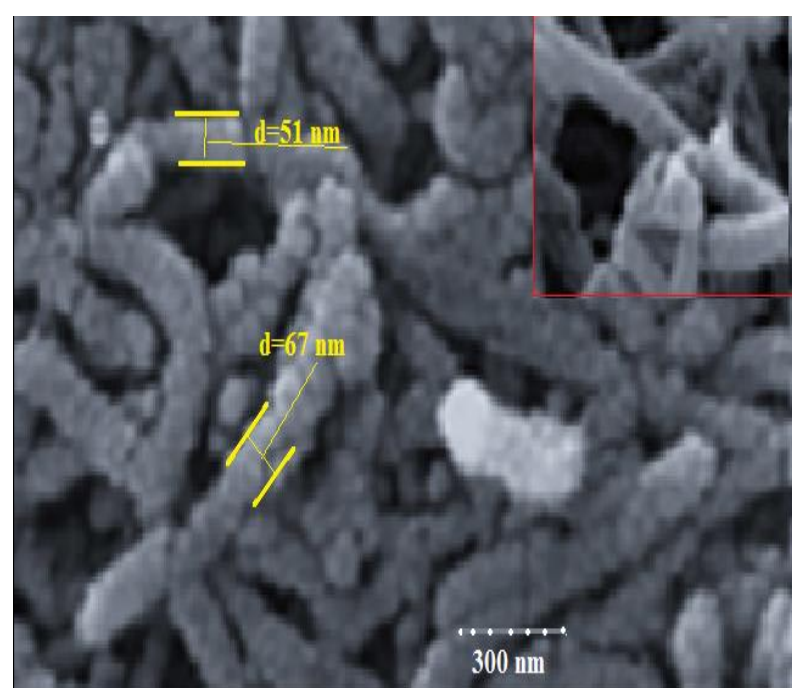

Fig. 4(a). SEM of CNTs@PhSO 3

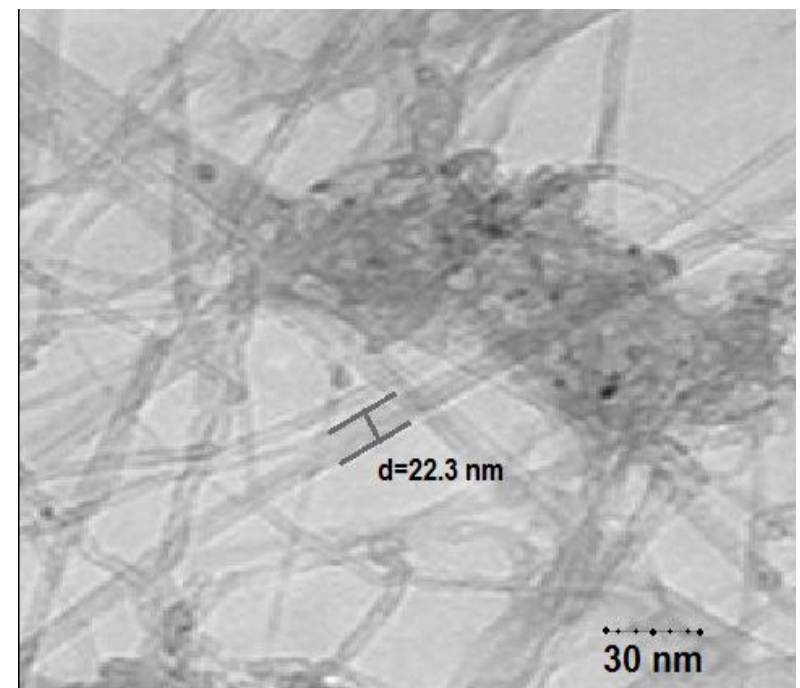

Fig. 4(b). TEM of CNTs@ $@ \mathrm{PhSO}_{3} \mathrm{H}$

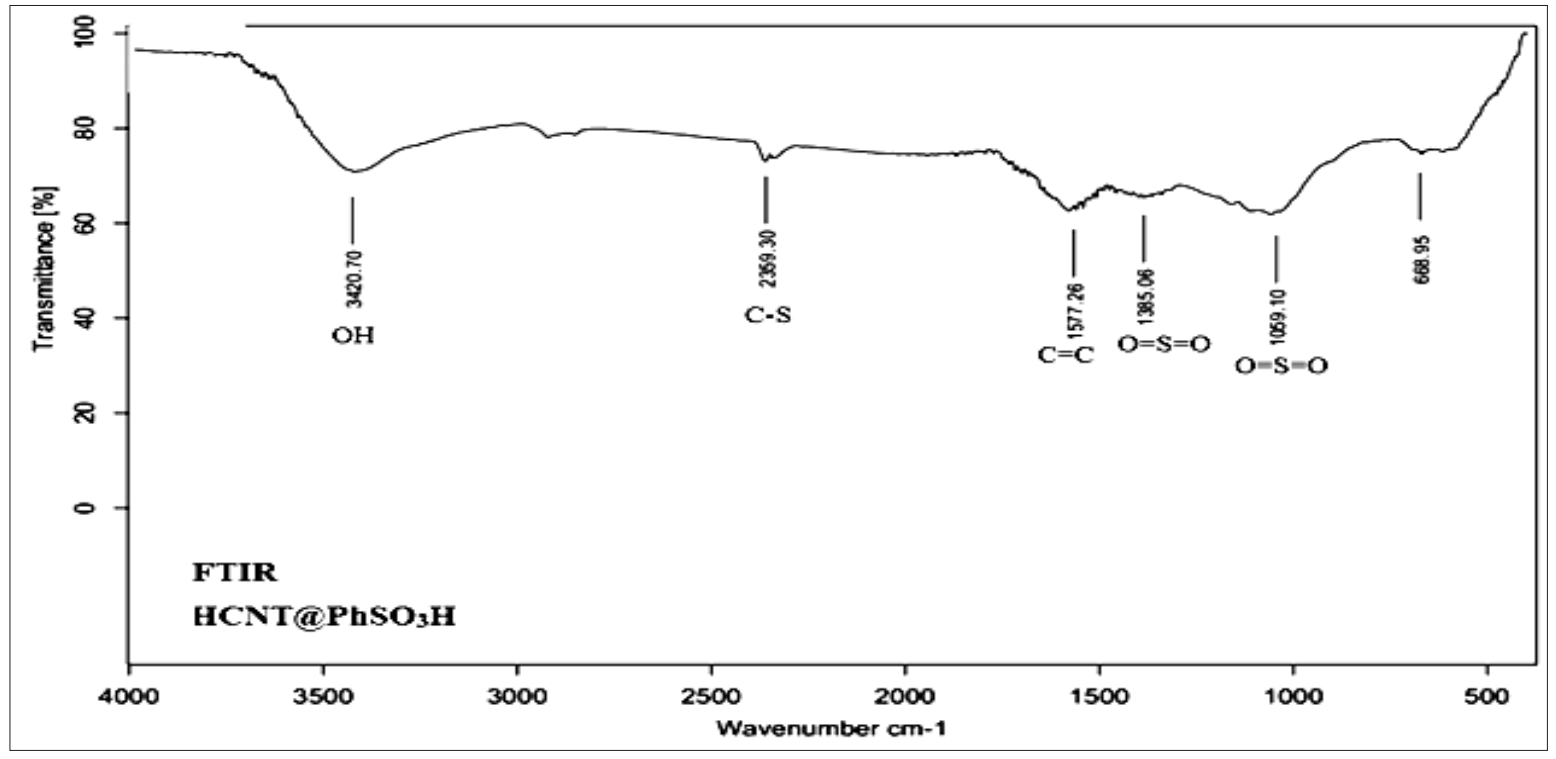

Fig. 5. FTIR spectrum of the $\mathrm{CNTs} @ \mathrm{PhSO}_{3} \mathrm{H}$ 


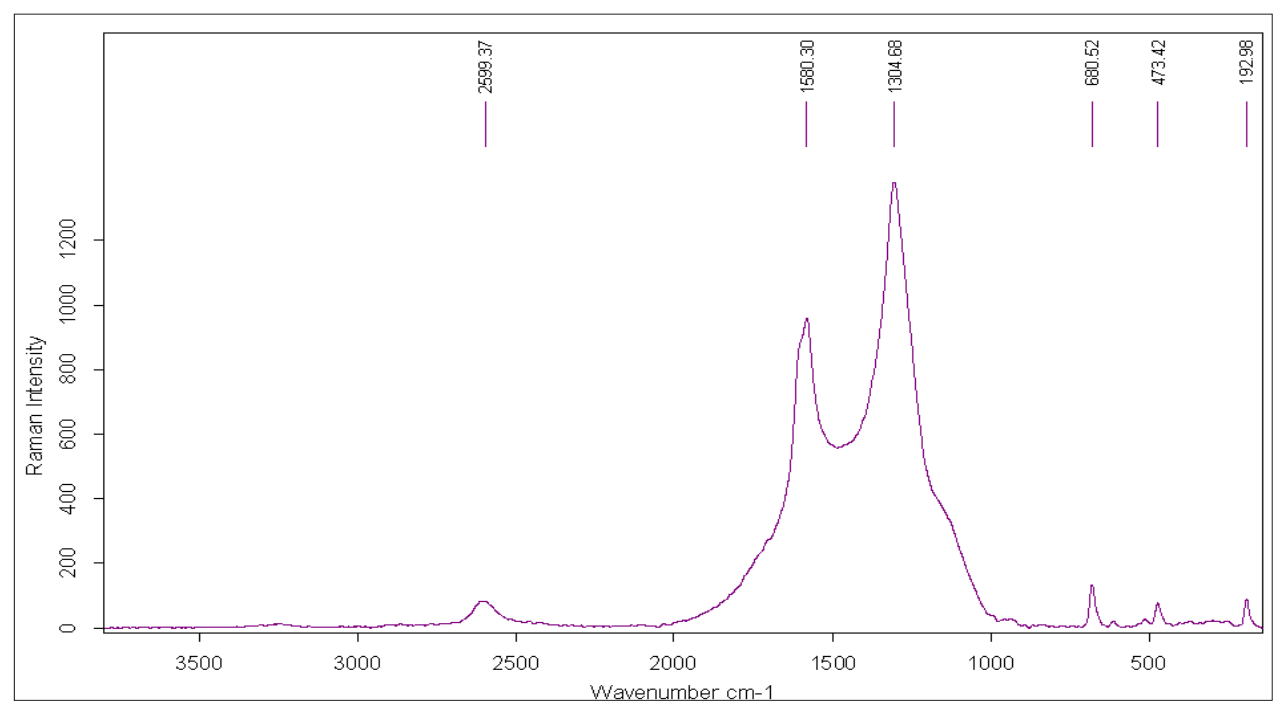

Fig. 6. Raman patterns of CNTs@ $\mathrm{PhSO}_{3} \mathrm{H}$

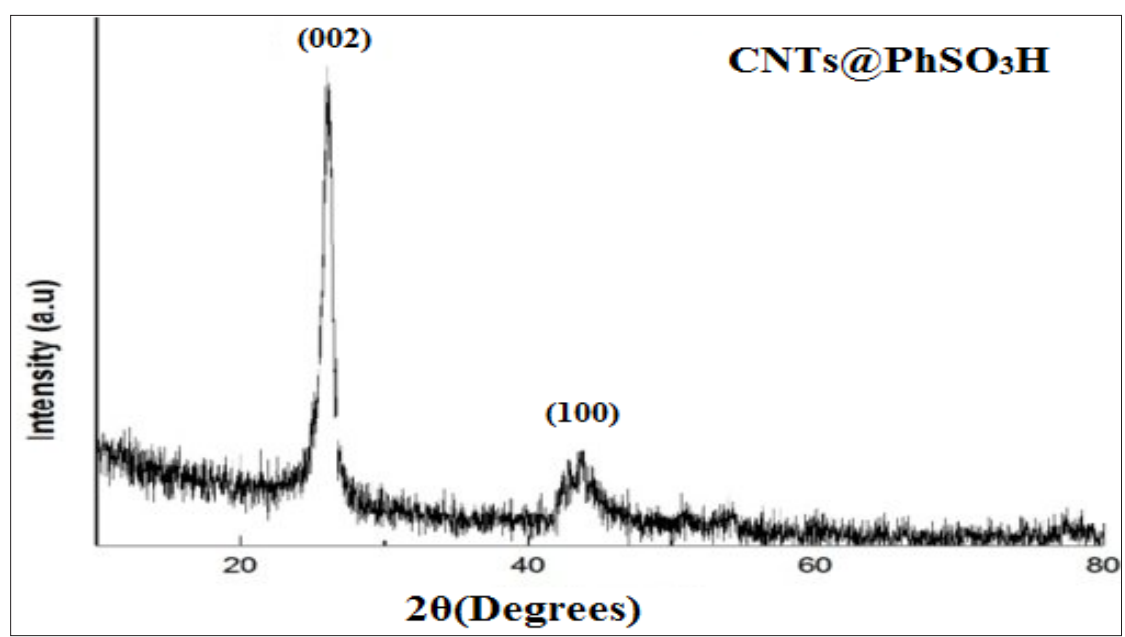

Fig. 7. XRD image of hexagonal structures in $\mathrm{CNTs} @ \mathrm{PhSO}_{3} \mathrm{H}$

\subsection{Optimization parameters}

The D- $\mu$-SPE procedure based on CNTs@ $\mathrm{PhSO}_{3} \mathrm{H}$ nanocomposite was used for extraction of benzene from well water and wastewater samples. The main effectiveness parameters such as, $\mathrm{pH}$, amount of CNTs@PhSO $\mathrm{H}$, volume of waters, adsorption capacity of sorbent were evaluated and studied. The $\mathrm{pH}$ sample is critical parameters and must be optimized. High adsorption of benzene from water samples based on CNTs@ $\mathrm{PhSO}_{3} \mathrm{H}$ nanocomposite depended on $\mathrm{pH}$ solution which was extracted by $\mathrm{D}-\mu$-SPE methods. The $\mathrm{pH}$ range $(1-12)$ was adjusted with buffer solution and the extraction efficiency of benzene in water samples was evaluated by benzene concentration $(0.1-10 \mathrm{mg}$ $\left.\mathrm{L}^{-1}\right)$ and $10 \mathrm{mg}$ of $\mathrm{CNTs} @ \mathrm{PhSO}_{3} \mathrm{H}$. The results showed, the recovery of extraction for benzene was decreased at acidic and basic $\mathrm{pH}$ ranges. Therefore, $\mathrm{pH}$ of 5.5-7.5 was selected as optimized $\mathrm{pH}$ for benzene extraction in waters (Fig. 8).

By D- $\mu$-SPE method, the amount of on CNTs@ $\mathrm{PhSO}_{3} \mathrm{H}$ nanocomposite was studied for $5 \mathrm{~mL}$ of water and wastewater samples. So, 1-20 mg of CNTs@ $\mathrm{PhSO}_{3} \mathrm{H}$ and CNTs was examined by proposed procedure. The results showed us, benzene in water samples can be efficiently extracted with 8 mg CNTs@ $\mathrm{PhSO}_{3} \mathrm{H}$ in optimized pH=7. So, 10 mg of CNTs@PhSO $\mathrm{H}$ nanocomposite was used as optimum mass for benzene extraction in waters (Fig. 9).

The sample volume (SV) in important factor and must be studied. So, the effect of sample 


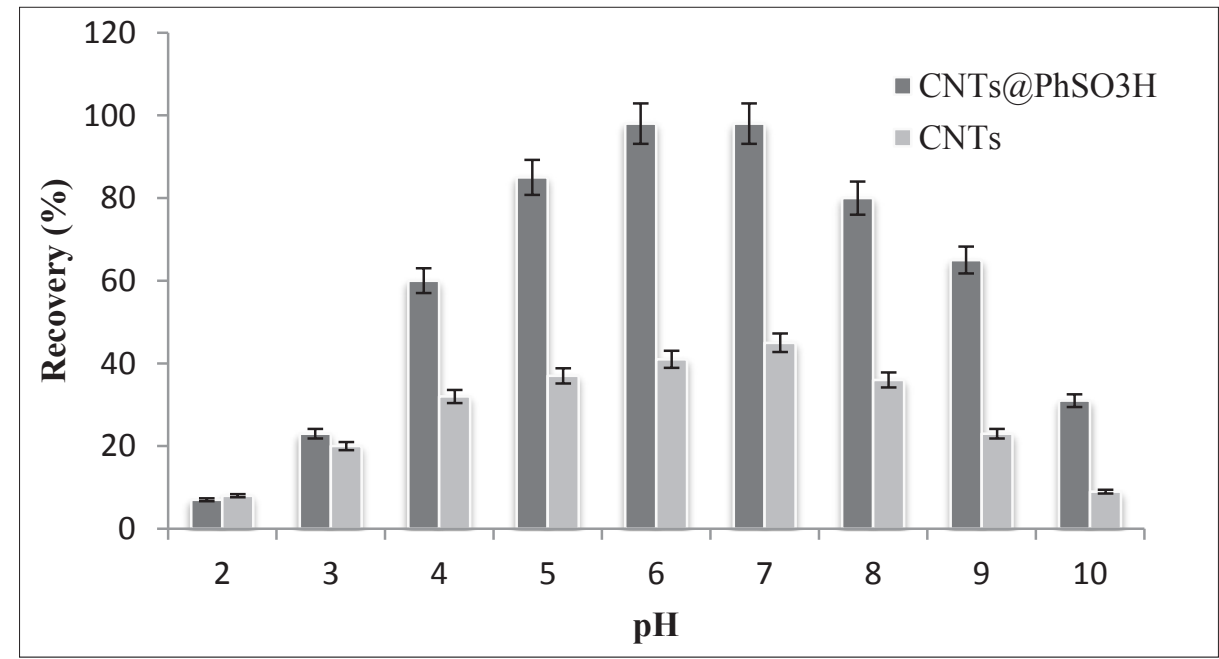

Fig. 8. The effect of $\mathrm{pH}$ on benzene extraction from water samples

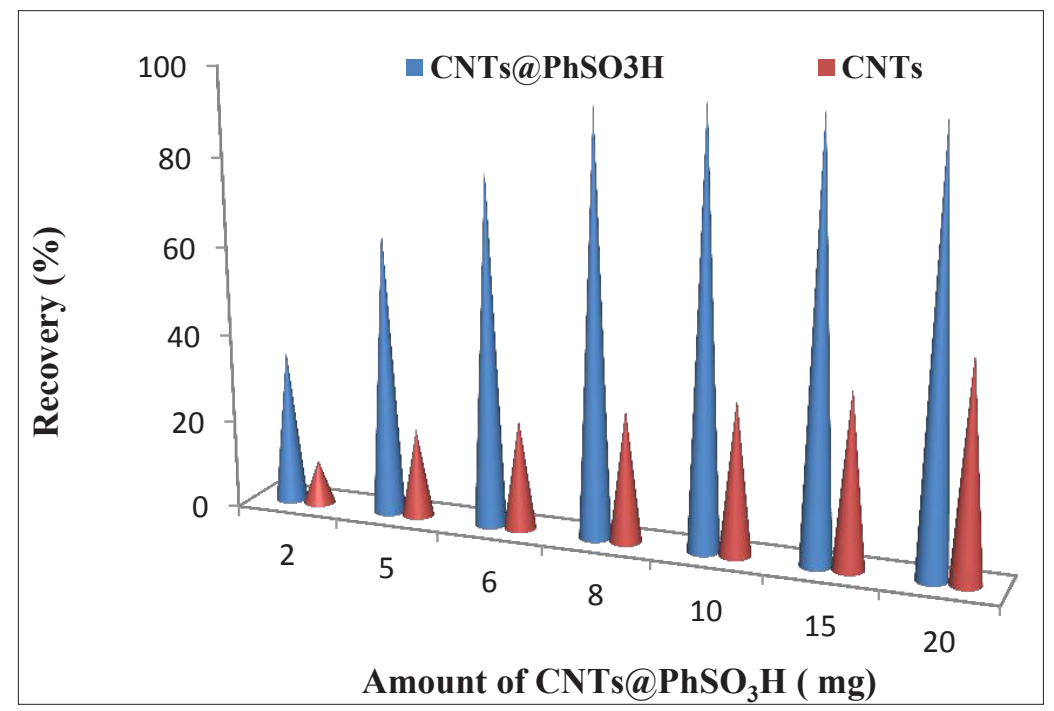

Fig. 9. The effect of amount of CNTs@ $\mathrm{PhSO}_{3} \mathrm{H}$ on benzene extraction by D- $\mu$-SPE method

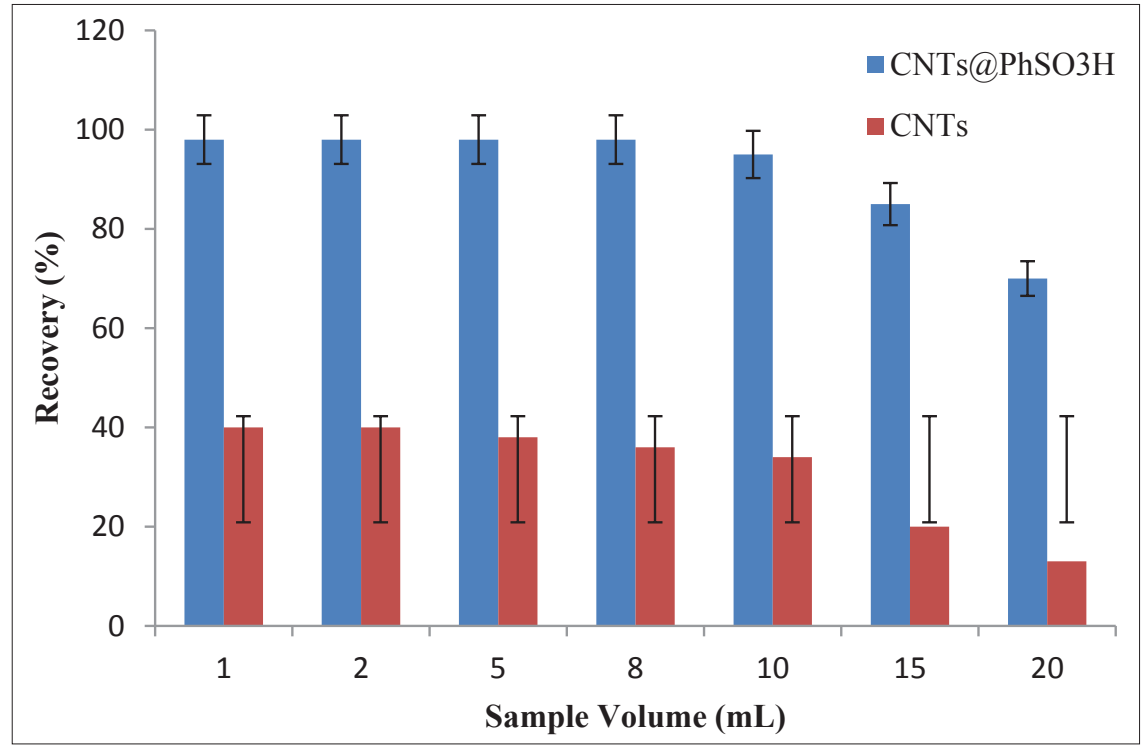

Fig 10. The effect of sample volume on benzene extraction by D- $\mu$-SPE method 
volume on benzene extraction in waters examined at optimized conditions. Due to procedure, the different water volumes between 1-10 $\mathrm{mL}$ with 10 $\mathrm{mgL}^{-1}$ of standard benzene solution were selected for benzene extraction by D- $\mu$-SPE methodology. As magnetic shaking for $10 \mathrm{~min}$, high recovery obtained for $10 \mathrm{~mL}$ of waters. Therefore, $5 \mathrm{~mL}$ of sample volume selected for further work (Fig. 10).

The validation methodology based on spiking well water and wastewater samples was achieved by concentration of standard benzene solution from LLOQ as $0.1 \mathrm{mgL}^{-1}$ and ULOQ as $10 \mathrm{mgL}^{-}$ ${ }^{1}$ by optimized conditions (Table 2 ). All samples analyzed by static head space gas chromatography mass spectrometry (SHS-GC-MS).

\subsection{Discussion}

This study set out with the aim of assessing the modification of CNTs with phenyl sulfonic acid group and its effect on the extraction efficiency of benzene in water samples. According to our results, it is revealed that compared to CNTs, CNTs@PhSA significantly adsorbs benzene in water. As table 3 , the results showed us the proposed method based on CNTs@PhSA had more efficient extraction of benzene from waters than CNTs sorbents which was presented by different authors [21-26]. Also the comparing of adsorption capacity(AC) of CNTs@PhSA (157.34 mg g-1 $)$ with other sorbents such as CNTs (22.86 $\left.\mathrm{mg} \mathrm{g}^{-1}\right)$, CuO-NPs (100.24 $\left.\mathrm{mg} \mathrm{g}^{-1}\right)$, GO/MOF-5 (77 $\left.\mathrm{mg} \mathrm{g}^{-1}\right)$, ZIF-8/GO(123 $\left.\mathrm{mg} \mathrm{g}^{-1}\right)$ and $\mathrm{GO}\left(158 \mathrm{mg} \mathrm{g}^{-1}\right)$ showed, the value of AC was near or more than others [27-30]. Osanloo at el was used graphene modified by ionic liquid (NG-IL) for toluene removal [31].

Table 2. The validation methodology based on CNTs@ $\mathrm{PhSO}_{3} \mathrm{H}$ by SHS-GC-MS

\begin{tabular}{lccc}
\hline samples & Added $\left(\mathbf{m g L}^{-1}\right)$ & *Found $\left(\mathbf{m g L}^{-1}\right)$ & Recovery $(\%)$ \\
\hline Well Water & ------ & $0.43 \pm 0.02$ & ---- \\
& 0.5 & $0.94 \pm 0.03$ & 102 \\
Paint Wastewater & ------ & $14.16 \pm 0.68$ & 98.1 \\
& 15 & $28.87 \pm 1.26$ & ------ \\
Oil-Factory Wastewater & ------ & $38.12 \pm 2.15$ & 96.8 \\
\hline
\end{tabular}

${ }^{*}$ Mean of three determinations \pm confidence interval $(\mathrm{P}=0.95, \mathrm{n}=10)$

Table 3. Comparing of dispersive micro solid phase extraction method based on CNTs@PhSA for benzene extraction from water samples with other published methods

\begin{tabular}{|c|c|}
\hline This Study & Relevant Studies \\
\hline $\begin{array}{l}\text { In this study, phenyl sulfonic acid group was } \\
\text { used for modification of CNTs in order to extract } \\
\text { benzene from water samples. }\end{array}$ & $\begin{array}{l}\text { CNTs have the capacity to be attached by functional groups. These } \\
\text { functional groups can change physical and chemical properties of } \\
\text { carbon nanotubes [21]. }\end{array}$ \\
\hline $\begin{array}{l}\text { zene concentration } \\
0,10 \mathrm{mg} / \mathrm{L}\end{array}$ & $\begin{array}{l}\text { concentration for the investigation of CNTs } \\
y \text { in benzene removal procedure is } 10 \mathrm{mg} / \mathrm{L}[22] \text {. }\end{array}$ \\
\hline Cor & $\begin{array}{l}\text { e mixture of CNTs and sample have been shaked for } 10 \text { minutes } \\
\text { ]. }\end{array}$ \\
\hline $\begin{array}{l}\text { Extra } \\
\text { shape }\end{array}$ & presenting \\
\hline images & eate a \\
\hline sts of randomly aggregat & ites o \\
\hline Addition of $\mathrm{SO}_{3} \mathrm{H}$ on $\mathrm{CNTs} @ \mathrm{Ph}$ had no change & According to SEM images of $\mathrm{H}_{2} \mathrm{SO}_{4}$-treated CNT \\
\hline $\begin{array}{l}\text { ge of } 5.5-7.5 \text { benzene } \\
\text { bles }\end{array}$ & $\begin{array}{l}\text { When } \mathrm{pH} \text { exceeds } 6.2 \text {, the adsorption efficiency increases } \\
\text { significantly [26]. }\end{array}$ \\
\hline
\end{tabular}




\section{Conclusions}

The main goal of the current study was to determine the effect of phenyl sulfonic acid group functionalization on the adsorption efficiency of CNTs for benzene removal in water samples. The adsorption mechanism is referred to the polar- $\pi$ and $\pi-\pi$ interaction between aromatic ring of benzene and surface sulfonic acid group as well as phenyl ring. Surprisingly, hexagonal structure of CNTs@ PhSA indicated no change in the basic structure of CNTs, after functionalization with $\mathrm{SO}_{3} \mathrm{H}$. However, the adsorption capacity of CNTs@ PhSA for benzene removal was significant. These findings suggest that in general, CNTs are capable of being modified and therefore, they represent a critical role in the adsorption of benzene and other pollutants. All concentration benzene in waters determined based on D- $\mu$-SPE procedure by SHSGC-MS. Under optimal conditions, adsorption efficiency of CNTs@PhSA and CNTs was obtained $97.7 \%$ and $20.6 \%$ for benzene removal from water samples, respectively.

\section{References}

[1] J.A. Kent, Riegel's handbook of industrial chemistry, Springer, 1992.

[2] C. Kent, Basics of toxicology, John Wiley \& Sons, Vol. 3, 1998.

[3] J.R. McKetta, Encyclopedia of Chemical Processing and Design: Volume 64-Waste: Hazardous: Management Guide to Waste: Nuclear: Minimization During Decommissioning. CRC press, 1998.

[4] H. Shim, E. Shin, S. T. Yang, A continuous fibrousbed bioreactor for BTEX biodegradation by a coculture of Pseudomonas putida and Pseudomonas fluorescens, Adv. Environ. Res.,7 (2002) 203-216.

[5] L. Mohammadi, E. Bazrafshan, M. Noroozifar, A. Ansari-Moghaddam, F. Barahuie, D. Balarak, Adsorptive removal of benzene and toluene from aqueous environments by cupric oxide nanoparticles: kinetics and isotherm studies, J. Chem., 2017 (2017) 2069519.

[6] US environmental protection agency, Pollutants, Code of federal regulations, Title 40, Washington, DC, 1996.
[7] ATSDR, Toxicological profile for lead, US Department of Health and Human Services Atlanta, GA, 2007.

[8] N. Wibowo, Adsorption of benzene and toluene from aqueous solutions onto activated carbon and its acid and heat treated forms: influence of surface chemistry on adsorption. J. Hazard. Mater., 146 (2007) 237-242.

[9] M. Aivalioti, I. Vamvasakis, E. Gidarakos, BTEX and MTBE adsorption onto raw and thermally modified diatomite, J. Hazard. Mater., 178 (2010) 136-143.

[10] S. Iijima, Helical microtubules of graphitic carbon. Nnat., 354 (1991) 56-58.

[11] S. Zhang, T. Shao, S.S. Kaplan Bekaroglu, T. Karanfil, The impacts of aggregation and surface chemistry of carbon nanotubes on the adsorption of synthetic organic compounds, Environ. Sci. Technol., 43 (2009) 5719-5725.

[12] A. J. Brooks, H.N, Lim, J.E. Kilduff, Adsorption uptake of synthetic organic chemicals by carbon nanotubes and activated carbons, Nanotechnol., 23 (2012) 294008.

[13] K.Yang, W. Xilong, Z. Lizhong, X. Baoshan, Competitive sorption of pyrene, phenanthrene, and naphthalene on multiwalled carbon nanotubes, Environ. sci. Technol., 40 (2006) 5804-5810.

[14] L. Ji, Ch. Wei, D. Lin, Z. Dongqiang, Mechanisms for strong adsorption of tetracycline to carbon nanotubes: a comparative study using activated carbon and graphite as adsorbents, Environ. Sci. Technol., 43 (2009) 2322-2327.

[15] H. H. Cho, B.A. Smith, J.D. Wnuk, D.H. Fairbrother, W.P. Ball, Influence of surface oxides on the adsorption of naphthalene onto multiwalled carbon nanotubes, Environ. sci. Technol., 42 (2008) 2899-2905.

[16] O.G. Apul, T. Karanfil, Adsorption of synthetic organic contaminants by carbon nanotubes: a critical review, Water res., 68 (2015) 34-55.

[17] C. Lu, Su. Fengsheng, Hu. Suhkai, Surface modification of carbon nanotubes for enhancing BTEX adsorption from aqueous solutions, Appl. Surf. Sci., 254 (2008) 7035-7041.

[18] F. Su, Lu. Chungsying, Hu. Suhkai, Adsorption of benzene, toluene, ethylbenzene and p-xylene by NaOCl-oxidized carbon nanotubes, Colloids and Surfaces A: Physicochem. Eng. Aspects 353 (2010) 
83-91.

[19] A. Rashidi, L. Roghayeh, F. Ehsaneh, Z. Masoud, Production of single-walled carbon nanotubes from methane over $\mathrm{Co}-\mathrm{Mo} / \mathrm{MgO}$ nanocatalyst: A comparative study of fixed and fluidized bed reactors, J. Nat. Gas chem., 20 (2011) 372-376.

[20] M.K. Abbasabadi, A. Rashidi, S. Khodabakhshi, Benzenesulfonic acid-grafted graphene as a new and green nanoadsorbent in hydrogen sulfide removal, J. Natural Gas Sci. Eng., 28 (2016) 87-94.

[21] F. Peng, Z. Lei, W. Hongjuan, Lv. Ping, Yu. Hao, Sulfonated carbon nanotubes as a strong protonic acid catalyst. carbon, 43 (2005) 2405-2408.

[22] B. Bina, M. Amin, A. Rashidi, H. Pourzamani, Benzene and toluene removal by carbon nanotubes from aqueous solution, Arch, Environ. Protect., 38 (2012) 3-25.

[23] S. Paliwal, S. Geib, C.S. Wilcox, Molecular torsion balance for weak molecular recognition forces. Effects of" tilted-T" edge-to-face aromatic interactions on conformational selection and solidstate structure. J. Am. Chem. Soc., 116 (1994) 4497-4498.

[24] E. I. Kim, S. Paliwal, C.S. Wilcox, Measurements of molecular electrostatic field effects in edge-toface aromatic interactions and $\mathrm{CH}-\pi$ interactions with implications for protein folding and molecular recognition, J. Am. Chem. Soc., 120 (1998) 1119211193.

[25] L. Zhang, F. Pan, X. Liu, L. Yang, X. Jiang, J. Yang, W. Shi, Multi-walled carbon nanotubes as sorbent for recovery of endocrine disrupting compoundbisphenol from wastewater, Chem. Eng. J., 218 (2013) 238-246.

[26] Y.H. Wang, S.H. Lin, and R.S. Juang, Removal of heavy metal ions from aqueous solutions using various low-cost adsorbents, J. Hazard. Mater., 102 (2003) 291-302.

[27] V. Kumar, Y. S. Lee, J. W. Shin, K. H. Kim, D. Kukkar, Y.F. Tsang, Potential applications of graphene-based nanomaterials as adsorbent for removal of volatile organic compounds, Environ. Int., 135 (2020) 105356.

[28] J. Cheng, L. Li, Y. Li, Q. Wang, C. He, Fabrication of pillar[5]arene-polymer-functionalized cotton fibers as adsorbents for adsorption of organic pollutants in water and volatile organic compounds in air, Cellulose, 26 (2019) 3299-3312.
[29] B.Y.Z. Hiew, L.Y. Lee, X.J. Lee, S. ThangalazhyGopakumar, S. Gan, S.S. Lim, G. T. Pan, T.C. K. Yang, W.S. Chiu, P.S. Khiew, Review on synthesis of 3D graphene-based configurations and their adsorption performance for hazardous water pollutants, Process Saf. Environ. Prot., 116 (2018) 262-286.

[30] H. Yan, H. Wu, K. Li, Y.W. Wang, X. Tao, H. Yang, A.M. Li, R.S. Cheng, Influence of the surface structure of graphene oxide on the adsorption of aromatic organic compounds from water, ACS Appl. Mater. Interfaces, 7 (2015) 6690-6697.

[31] M. Osanloo, O. Qurban Dadras, Nobel method for toluene removal from air based on ionic liquid modified nano-graphen, Int. J. Occup. Hyg., 6 (2014) $1-5$. 